\title{
Recent significant decline of strong carbon peat accumulation rates in tropical Andes related to climate change and glacier retreat
}

Romina Llanos, Patricia Moreira-Turcq, Bruno Turcq, Raúl Espinoza Villar, Yizet Huaman, Thomas Condom, Bram Willems

Correspondence to: Romina Llanos (rominallanos@outlook.com)

Table S1: Average and standard deviation values of bulk density $\left(\mathrm{g} \mathrm{cm}^{-3}\right)$, organic matter $(\%)$, organic carbon $(\%)$, carbon stable isotope $\delta^{13} \mathrm{C}(\%)$ and carbon accumulation rates $\left(\mathrm{gC} \mathrm{m}^{-2} \mathrm{yr}^{-1}\right)$ for the four peat cores.

\begin{tabular}{|c|c|c|c|c|}
\hline \multirow{2}{*}{$\begin{array}{c}\text { Peatlands } \\
\text { Cores }\end{array}$} & \multicolumn{2}{|c|}{ APA 1} & \multicolumn{2}{|c|}{ APA 2} \\
\hline & APA1-C1 & APA1-C5 & APA2-C3 & APA2-C4 \\
\hline $\begin{array}{l}\text { Bulk Density } \\
\quad\left(\mathrm{g} \mathrm{cm}^{-3}\right)\end{array}$ & $0.088 \pm 0.034$ & $0.132 \pm 0.055$ & $0.075 \pm 0.025$ & $0.078 \pm 0.024$ \\
\hline $\begin{array}{c}\text { Organic Matter } \\
(\%)\end{array}$ & $96.5 \pm 1.2$ & $96.0 \pm 1.3$ & $92.7 \pm 2.8$ & $90.8 \pm 3.0$ \\
\hline $\begin{array}{c}\text { Organic Carbon } \\
(\%)\end{array}$ & $51.1 \pm 0.6$ & $50.9 \pm 0.7$ & $49.1 \pm 1.5$ & $48.1 \pm 1.6$ \\
\hline $\begin{array}{l}\delta^{13} \mathrm{C} \\
(\% 0)\end{array}$ & & $-25.40 \pm 0.69$ & & $-25.36 \pm 0.69$ \\
\hline $\begin{array}{l}\text { C Accumulation Rate } \\
\qquad\left(\mathrm{gC} \mathrm{m}^{-2} \mathrm{yr}^{-1}\right)\end{array}$ & $400.1 \pm 206.2$ & $546.7 \pm 264.5$ & $239.0 \pm 100.2$ & $193.6 \pm 53.0$ \\
\hline
\end{tabular}




\section{Total Organic Carbon (\%)}

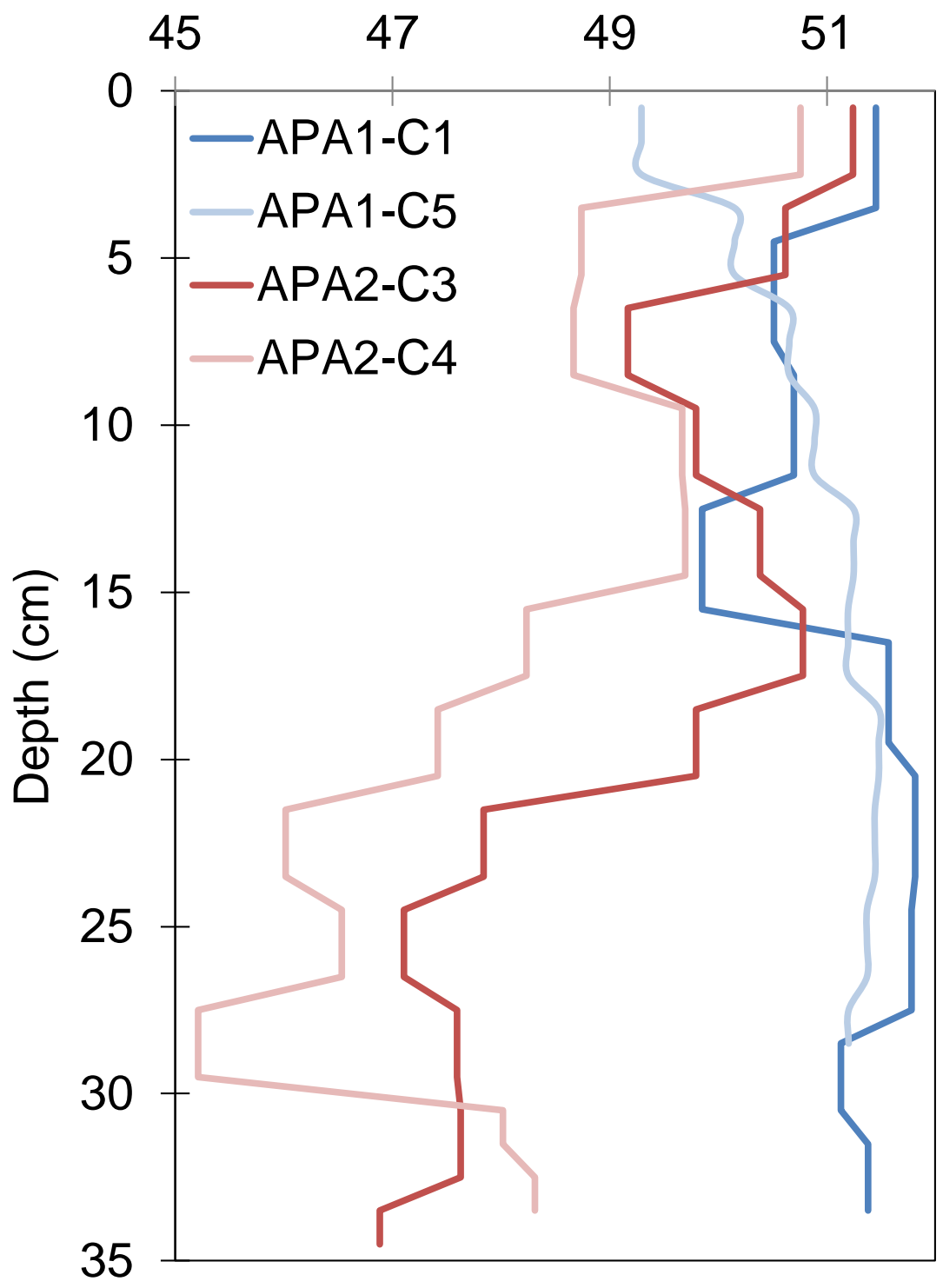

Figure S1: Total organic carbon (TOC, \%) contents for the four peat cores: APA1-C5 and APA2-C4 at $4200 \mathrm{~m}$ asl, and APA2-C3 and APA2-C4 at $4420 \mathrm{~m}$ asl. 